Archives

$21 \mid 1998$

1. Pour une histoire comparée du voeu // 2. Les

Cagots

\title{
Présentation
}

\section{Alain Boureau}

\section{OpenEdition}

Journals

Édition électronique

URL : http://journals.openedition.org/ccrh/2504

DOI : $10.4000 /$ ccrh. 2504

ISSN : $1760-7906$

Éditeur

Centre de recherches historiques - EHESS

Édition imprimée

Date de publication : 1 novembre 1998

ISSN : 0990-9141

Référence électronique

Alain Boureau, « Présentation », Les Cahiers du Centre de Recherches Historiques [En ligne], 21 | 1998, mis en ligne le 20 avril 2009, consulté le 21 septembre 2020. URL : http://journals.openedition.org/ ccrh/2504; DOI : https://doi.org/10.4000/ccrh.2504

Ce document a été généré automatiquement le 21 septembre 2020.

Article L.111-1 du Code de la propriété intellectuelle. 


\title{
Présentation
}

\author{
Alain Boureau
}

1 Cette livraison des Cahiers $d u C R H$ poursuit la publication de travaux réalisés au Centre lors de journées de recherche et de discussion. Nous suivons le même principe : livrer rapidement des résultats, parfois encore partiels et incertains, qui pourront être repris ailleurs sous une forme plus élaborée. Nous avons donc réuni ici certaines interventions proposées aux III $^{\mathrm{e}}$ et $\mathrm{IV}^{\mathrm{e}}$ journées sur le vœu (juin 1997 et juin 1998). Pierre-Antoine Fabre et moi-même continuons à organiser ces journées annuelles, suivant les visées comparatives présentées dans le numéro 16 des Cahiers. Graduellement, l'horizon s'élargit, les analyses s'approfondissent. Des lacunes, des interrogations demeurent ; la présente publication vaut aussi comme appel d'offres, et comme incitation aux critiques et suggestions. Nous pensons tenir en 1999 une cinquième et dernière série, avant de passer au stade final d'un colloque et/ou d'un ouvrage systématiquement organisé. Les participants de ces journées qui n'ont pas souhaité donner un texte immédiatement, y trouveront leur place.

2 Une demi-journée de discussions avait été organisée le 14 février 1997 sur la question des Cagots du Béarn, cette mystérieuse "caste » dominée que l'on repère depuis le Moyen Âge central jusqu'aux temps modernes. Le principe est ici de faire débattre notre ami Alain Guerreau, auteur, en collaboration avec Yves Guy, d'un livre retentissant sur la question, Les Cagots du Béarn (Paris, 1988), d'une part avec Enric Porqueres, anthropologue (EHESS), qui consacre une partie de ses recherches actuelles aux « races maudites» (à la suite de ses travaux sur les juifs convertis de Majorque ; voir son livre Lourde alliance), d'autre part, avec Benoît Cursente (CNRS, Toulouse, UMR 5591), spécialiste de l'histoire sociale de la Gascogne médiévale, dont la somme Des maisons et des hommes. La Gascogne médiévale $\mathrm{XI}^{e}-\mathrm{XV}^{e}$ siècle, vient d'être publiée.

La précédente livraison avait fait connaître les travaux d'un groupe récemment créé au CRH par Christian Jouhaud et Alain Viala, le GRIHL. Ce numéro présente brièvement un nouveau groupe de recherche au sein du Centre, consacré au Livre de droit, auquel les pages des Cahiers seront largement ouverte... 